\title{
Is this time different? How digitalization influences job creation and destruction ${ }^{\text {मे }}$
}

\author{
Benjamin Balsmeier ${ }^{\mathrm{a}, \mathrm{b}}$, Martin Woerter ${ }^{\mathrm{b}, *}$ \\ ${ }^{a}$ University of Luxembourg, Luxembourg \\ ${ }^{\mathrm{b}}$ ETH Zurich, KOF Swiss Economic Institute, Switzerland
}

\section{A R T I C L E I N F O}

\section{Keywords:}

Digitalization

Employment

Innovation

Job creation

Job destruction

Technological change

\begin{abstract}
A B S T R A C T
With the process of digitalization now in full swing, many are wondering how the adoption of new technologies influences job creation and destruction. Much hinges upon the specific tasks that machines take on and how many new tasks are created through the adoption of new digital technologies. Some argue that most tasks that are at risk of automation are those performed by rather low- to medium-skilled employees, while most new tasks that emerge from the adoption of digital technologies complement high-skilled labor. We present evidence derived from representative survey data from Switzerland that is consistent with this view. Specifically, we find that increased investment in digitalization is associated with increased employment of high-skilled workers and reduced employment of low-skilled workers, with a slightly positive net effect. The main effects are almost entirely driven by firms that employ machine-based digital technologies, e.g. robots, 3D printing or the Internet of Things. We do not find any significant employment effects when non-machine-based digital technologies are considered, e.g. ERP, e-commerce or cooperation support systems.
\end{abstract}

\section{Introduction}

There is widespread consensus among both academics and practitioners that innovation is the main driver of productivity, economic growth and job creation. Whether this holds true with regard to innovations that fall under the umbrella of 'digitalization' is a subject of vigorous debate, though. This debate is particularly controversial when it comes to the impact of digitalization on job creation and destruction.

Indeed, for more than a century, bookshelves have been filled with analyses on how technological development influences jobs. Many prominent academics have argued - and some still argue - that man and machine are in a race, which machines will eventually win, leading to mass unemployment (e.g. Leontief, 1952; Ford, 2015). Historical examples of jobs that were washed away by technological developments seem to confirm this view, e.g. stoker that were replaced by electrical engines. At the same time, it is not a controversial statement that many new jobs were created in the wake of technological developments of the past (e.g. Landes, 1969; Chandler, 1977; Mokyr, 1990). After all, consistent with Schumpeter's concept of creative destruction, the net impact on jobs seems to be positive (Mastrostefano and Pianta, 2009; Kogan et al., 2017). ${ }^{1}$ The crucial, yet unanswered, question is whether this time is different.

One way to think about potential job creation and destruction conceptually is to differentiate between tasks that are regularly performed by human beings but could be performed equally well or more efficiently by machines, versus tasks that cannot be substituted by machine work, or new complementary tasks that are created because of machine adoption. Many politicians and employees feel challenged by the ongoing digital revolution because the new technologies behind it often seem to be direct substitutes for tasks that are regularly performed by human beings. Some technologies enable far-reaching changes of established production lines, e.g. through intelligent platform designs that render intermediaries obsolete or shift of tasks from employees to customers. Also, unlike many other technological developments of the past, digitalization is a general-purpose technology, i.e. it can be adopted across a wide range of industries, including the service sector (Brynjolfsson and McAfee, 2016). In a frequently cited study on tasks that are susceptible to automation through digital technologies,

\footnotetext{
The authors wish to thank Andrin Spescha and Gilles Aubert for invaluable research assistance. We would also like to thank Gudela Grote, Toni Wäfler, and

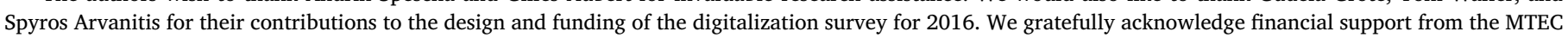
Foundation at ETH Zurich. Any errors and omissions remain the authors'.

* Corresponding author.

E-mail address: woerter@kof.ethz.ch (M. Woerter).

${ }^{1}$ For a comprehensive overview and broader discussion of the relationship between innovation and employment see Pianta (2006).
} 
robotics and artificial intelligence, Frey and Osborne (2017) conclude that $47 \%$ of jobs in the U.S. are at risk of becoming redundant. ${ }^{2}$

However, these numbers are unlikely to hold true (e.g. Arntz et al., 2017; Autor, 2015; Dengler and Matthes, 2015) and, even if they would turn out to be true, it is by no means clear that the world would be facing a future of prevalent mass unemployment. Coinciding with the evolution of information and communication technologies (ICT) over the last few decades, plenty of new tasks, such as programming and data analysis, have been created that are still hard to automate via machine work (Acemoglu and Restrepo, 2017a). These ICT-induced technological developments, which might well be viewed as early advances of digitalization, contributed to the emergence of whole new industries that nowadays employ millions of workers performing tasks that formerly did not exist. Few had foreseen such developments at a time when companies like Facebook and Amazon had not even been founded.

Conceptually it is crucial to note two things. The tasks that become obsolete due to digital technologies are typically of a different kind than the tasks created, and different types of digital technologies may have heterogeneous effects on skill requirements. Robots, for instance, typically compete quite directly with manual labor that requires a low to medium skill level. Tasks that are created, on the other hand, typically require a rather high skill level and are relatively few in total. Since jobs are defined by the tasks to be fulfilled, a change in the demand for certain tasks may simultaneously lead to the creation and destruction of jobs with heterogeneous skill requirements. Over the last decade, for instance, research has found an increase in jobs for high-skilled and low-skilled workers, while jobs for medium-skilled labor were in decline (e.g. Autor et al., 2003; Goos and Manning, 2007; Goos et al., 2009; Michaels et al., 2014). This job polarization can be attributed to technological change, but it is not clear which types of technologies caused these employment effects and whether technologies summarized under the umbrella of digitalization lead to similar effects.

So far, the literature has been unable to empirically link within firm changes in investment in digitalization with within firm changes in employment across different skill groups. The present paper aims to address this gap in the literature in two steps. First, we will estimate standard models of employment changes in different skill categories on changes in investment in digitalization. In a second step, we propose and empirically confirm a differentiation between the impact of nonmachine-based digital technologies, such as ERP, social media, or ecommerce, and rather complex machine-based digital technologies, such as robots, 3D printing or the Internet of Things. Technically, machine-based technologies are characterized by a powerful combination of data access, computation and communication technologies with acting hardware. This gives machine-based digital technologies their disruptive power, and it is these technologies in particular that are supposed to drive the current industrial revolution (Rifkin, 2013).

Our empirical analysis is based on representative data from two surveys. $^{3}$ We exploit firm-level information on investment in

\footnotetext{
${ }^{2}$ While the proportion of jobs at risk is even higher (57\%) if all Western economies are taken into account (Schwab, 2016) the numbers reflect only theoretical potentials and appear to be strongly upward biased. Once taking into account workers' ability to adapt and switch tasks within jobs, these figures decline strongly, see e.g. Arntz et al. (2017). Second, these figures solely reflect theoretical technological potentials. The employment effects of these theoretical technological potentials are probably very different, as discussed by Autor (2015).

${ }^{3}$ Both surveys are based on the same representative sample of firms with at least 20 full-time equivalent employees and were carried out by the KOF Swiss Economic Institute in cooperation with the Chair of Work and Organizational Psychology at the Department of Management, Technology, and Economics at the ETH Zurich, and the University of Applied Sciences and Arts Northwestern Switzerland, School of Applied Psychology in 2016 and by the KOF Swiss Economic Institute in 2015. Similar data exists for Germany, and has been
}

digitalization and on the adoption of a rich list of specific digital technologies that ranges from well-known technologies such as ERP, customer relationship management (CRM), supply chain management (SCM) systems, e-commerce and robots to fairly recently adopted technologies such as social media, cloud computing, 3D printing, autonomous vehicles, and the Internet of Things.

Consistent with the literature and recent advances in economic theory (Acemoglu and Restrepo, 2017a), we find that investment in digitalization is associated with increased employment of high-skilled labor whereas low- and medium-skilled labor tends to decline or remain unaffected. Separate examinations of firms that adopt complex machine-based digital technologies and firms that use non-machine-based digital technologies reveal heterogeneous effects. Only machine-based technologies driving the current industrial revolution are responsible for significant employment effects. The estimated impact of investment in digitalization is distinct from investment in general research and development (R\&D) and, while important limitations remain, all results survive controls for firm fixed effects and several robustness and sensitivity checks.

The investigation contributes to at least two strings of literature. First, we complement research in economics on the impact of innovation on employment growth. Most prior studies on the topic have found positive influences of innovation on employment at the firm level (e.g. Blanchflower and Burgess, 1999; Van Reenen, 1997; Entorf and Pohlmeir, 1990; Smolny, 1998; Balsmeier and Delanote, 2015). Different types of innovation, e.g. product vs. process innovations, can have differing impacts, though, and the net influence depends on the chosen strategies for innovation and varies across industries (Mastrostefano and Pianta, 2009). In the long run, the overall positive impact holds at the industry level; even after taking complex dynamics of the relationship into account (Mastrostefano and Pianta, 2009). While this literature achieved quite a deep level of understanding, empirical analyses often had to rely on rather broad measures of innovation, e.g. R\&D expenses or innovation counts, which inhibit more fine-grained analyses of specific technological developments in a systematic way. Our data help us to overcome this limitation by enabling us to link within firm changes specifically in investments in digitalization to within firm changes in jobs with differing skill requirements. Related studies analyze changes in the casualization of work and work contracts that are caused by the process of digitalization (e.g. AubertTarby et al., 2018) or provide in-depth analyses of a single technology, e.g. 3D-printing (Rayna et al., 2015). Arntz et al. (2018), on the other hand, estimate the net impact of digitalization on employment for the whole German economy, using a rigorous structural model. Consistent with our findings, they report a small positive net effect. Both their and our result run counter to the overly negative prediction by Frey and Osborne (2017), which has received much attention by politicians and the popular press although it does not hold up to more rigorous approaches (Arntz et al., 2017). Apart from a contribution the scientific literature, our study thus contributes to the public debate on how digitalization influences job destruction and creation. In line with prior literature on job polarization (e.g. Autor et al., 2003; Goos and Manning, 2007; Oesch and Rodriguez Menes, 2011) our study suggests to expect heterogeneous employment effects across skill groups. It supports former findings of increased demand for high-skilled labor and lower demand for medium-skilled labor but differs with respect to lowskilled labor. While former studies showed that demand for low-skilled workers increased in response to technological changes of the past decades, we find that firms' investment in digitalization is associated with a decline in firms' low-skilled workers. Due to the restriction of our empirical setup to a single country and rather small dataset of firms

(footnote continued)

analyzed with a different focus elsewhere (e.g. Arntz et al., 2018; Lehmer and Matthes, 2017; Arntz et al., 2016). 
with at least 20 employees in 2015 , it is too early to safely conclude that digitalization will have different effects on low-skilled labor than technological developments of the past. The present study provides an early snapshot of a potentially important change though, which deserves further attention by future studies. It also points to a largely neglected heterogeneity across technologies that is often masked by more aggregated data.

\section{Institutional background - a snapshot of the Swiss economy}

Before jumping to the analysis section, it is worthwhile looking at the institutional background of our empirical setting. Switzerland is a technologically advanced, small and open economy. It is the most innovative country in Europe according to the European Innovation Scoreboard 2017 and it is also ranked among the most competitive countries in the world (WF Ranking, 2016-2017, Bris and Cabolis, 2017). Related to this performance, we observe a rather stable industry structure, which is strongly exposed to international competition. About $53 \%$ of manufacturing firms with more than five employees are exporters, and the average sales share of exports amounted to $36 \%$ in 2014. Also, the service sector is significantly exposed to international competition; $33 \%$ of service firms are exporters, and the average sales share amounts to $12 \%$. While we have observed an increase in the economic importance of the service sector in countries like the U.S., the Netherlands, and some Scandinavian countries, Switzerland's manufacturing sector has remained a mainstay of the country's economy; its share in value added only slightly decreased from $28 \%$ in 1991 to $25 \%$ in 2010 (Arvanitis et al., 2014).

The international competitiveness of the Swiss economy is partly due to the effectiveness of the education sector. It contributes to the high employment rate and the large proportion of well-educated people. The total employment rate of $80 \%$ is the second highest in Europe (Eurostat, 2016). Switzerland has a comprehensive vocational training system that is often seen as the backbone of its manufacturing excellence. It provides workers with specialist skills, which makes them a highly sought-after workforce in several sectors. Overall, the Swiss employees are well educated. The share of high-skilled employees (tertiary degree) amounts to $29 \%$, the share of employees with a midskilled level (secondary school for general education and vocational education) and the share of low-skilled labor (compulsory school) amounts to $61 \%$ and $10 \%$ respectively (FSO (Federal Statistical Office), 2018a).

A high employment rate with well-educated staff has its price. Switzerland ranks second among European countries in terms of salaries per working hour. The average Swiss employee earned 62.01 CHF (CHF $1 \cong$ USD $1.02 \cong$ EUR 0.90 ) per hour in 2012. Only Norway has higher salaries. ${ }^{4}$ Although labor costs are very high, the labor share has remained stable since the 1980s (Siegenthaler and Stucki, 2015).

Given its large manufacturing sector, its technological expertise and its well-educated labor force, the Swiss economy should be very receptive to the adoption of digital technologies. Indeed, $29 \%$ of firms use robots, $12 \%$ use $3 \mathrm{D}$ printing, and $10 \%$ use Internet-of-Things applications (see Appendix, Table A1 for details). Owing to the increasing investment in these and other digital technologies over the last few years, many expect the demand for skills to change, which is an important field of investigation and the main subject of the paper at hand.

\footnotetext{
${ }^{4}$ If we correct for purchasing power, Switzerland - with an hourly wage of $36.65 \mathrm{CHF}$ - remains among the three countries with the highest compensation, ranking third after Norway and Belgium (FSO (Federal Statistical Office), 2016).
}

\section{Empirical investigation}

\subsection{Data}

In order to investigate the consequences of investment in digitalization for job creation and destruction we draw on two datasets.

First, we use data from a unique representative survey on the digitalization activities of Swiss firms. ${ }^{5}$ The main goal of the survey was to provide a comprehensive overview of the adoption of fairly complex machine-based and non-machine-based digitalization technologies in the private sector. The survey includes detailed information on the educational attainment of firms' employees along other firm characteristics, e.g. research and development expenditures. The survey was carried out in 2016. It followed the same professional standards (sampling techniques, non-response control etc.) that are regularly used for the well-known Community Innovation Surveys, which have been extensively studied in the past. ${ }^{6}$

Second, we use data from the Swiss Innovation Survey (SIS) 2015, which is equivalent to the Community Innovation Survey in the EU member states. The data proved to be reliable and robust against statistical biases in terms of 'type of questions' or 'common response bias' (Podsakoff et al., 2003; Keupp and Gassmann, 2013). Although the questionnaire includes qualitative questions, we only use quantitative information for the study at hand. Potential imprecision in qualitative answers or 'subjective' answers should thus not affect this investigation.

Both surveys are based on the KOF enterprise panel, which is a representative sample of Swiss firms, comprising 5700 firms in total. The panel is a stratified random sample of firms with more than five employees. Stratification refers to 34 industries and within each industry to three firm-size classes. It covers the manufacturing, construction, and service sectors. The response rate amounted to $30 \%$ in both surveys. ${ }^{7}$ For the present study we restricted the sample to firms with at least 20 employees in 2015 , because only for these firms were information about their digital investments requested in both surveys. ${ }^{8}$ Finally, we merged both surveys at the firm level based on the unique time-invariant firm identifier of the KOF enterprise panel, allowing us to assemble information on two points in time, 2014 and 2015, per firm. This approach improves identification (see below) at the expense of a loss in observations of firms with fewer than 20 employees and those

\footnotetext{
${ }^{5}$ The digitalization survey was conducted by the ETH Zurich, KOF Swiss Economic Institute, the Chair of Work and Organizational Psychology at the Department of Management, Technology, and Economics at the ETH Zurich, and the University of Applied Sciences and Arts Northwestern Switzerland (FHNW), School of Applied Psychology (APS).

${ }^{6}$ For more information about the survey and comprehensive descriptive statistics, see Arvanitis et al. (2017).

${ }^{7}$ The authors are part of the team that collected the data and have in-depth knowledge of the questionnaires and the survey process. The response rate is quite satisfactory, given that both surveys are not compulsory. A comprehensive non-response control and targeted recalls significantly increase the survey response rates and guarantee sufficient coverage in all cells (34 industries times three firm-size classes). Due to item non-response we lose 145 observations. In the first-difference setting we do not detect any item non-response for employment and R\&D activities, however, there are missing values of the expenditures for digital technologies.

${ }^{8}$ The company size distribution in the population is much skewed. Like in many other countries, very small companies are dominating. According to the enterprise census in Switzerland (provisional data for 2016) 90\% of all companies have between 1 and 9 employees (full-time equivalent). $8 \%$ have between 10 and 49 employees, $1.5 \%$ have between 50 and 250 employees, and $0.3 \%$ are large companies with more than 250 employees (FSO (Federal Statistical Office), 2018b). It is important to note however, that in total $50 \%$ of the employees work in companies with more than 50 employees (FSO (Federal Statistical Office), 2018c). Hence, our data covers a large share of the economic activity in Switzerland, although it is representative only for firms with at least 20 employees.
} 
that responded only in one survey to all questions of interest. ${ }^{9}$ Comparing the descriptive statistics of the final sample with the non-merged cross-sectional data revealed that the restriction to firms observed twice did not cause a sample selection bias (see Tables A2a, A2b and A3 in the Appendix). ${ }^{10}$

\subsection{Measurement of educational attainment}

In order to disentangle potential differences in job creation and destruction across jobs with heterogeneous skill requirements we differentiate between three levels of formal education. The category 'highskilled' contains workers with professional tertiary education (ISCED97 4), including graduates from universities of applied sciences (ISCED 5b) and conventional universities (ISCED97 $5 \mathrm{a}$ and 6). The category 'midskilled' refers to workers with completed upper secondary education (ISCED97 3) and workers who have finished vocational education and training (VET) rather than a general upper secondary education. The third category ('low-skilled') comprises untrained workers and dual VET students (ISCED97 1 and 2). VET refers to upper secondary education that prepares students for labor market entry. Dual VET refers to upper secondary education that combines classroom education and workplace training. These students typically work in the firm for about three days per week and spend the remaining time in classroom education. This education usually takes three to four years to complete. Since these students cannot be employed like fully trained workers, we follow the literature and combine them with untrained workers in the category 'low-skilled' (Bolli et al., 2017).

The descriptive statistics show that firms created on average about 14 high-skilled jobs, while they reduced mid-skilled jobs by about four employees and low-skilled jobs by about nine employees. In total the average firm created two jobs in the period under investigation.

\subsection{Measurement of digitalization}

Our main explanatory variable is firms' investment in digitalization. For the study at hand we look at changes in investment between 2014 and 2015. The descriptive statistics show that the average firm spent about CHF 620,000 (CHF $1 \cong$ USD $1.02 \cong$ EUR 0.90 ) on digitalization and increased their digital investment from 2014 to 2015 by around CHF 84,000 , i.e. $13.5 \%$. The average firm is of medium size, has 273 employees, and invests about CHF 1.138 million in R\&D (Table 1 provides further descriptive statistics in levels of 2015. Table A3 in the Appendix shows descriptive statistics of the differenced variables and corresponding correlations are presented in Table A4).

In order to get a grasp of the heterogeneous influence of different digital technologies on job creation and destruction we differentiate between the adoption of fairly complex machine-based digital technologies, which are supposed to drive the current industrial revolution, and other non-machine-based technologies, which are regularly adopted by a wide range of firms across all industries. It is assumed that the complexity and challenges of digital technologies and also their consequences for employment differ between both categories. This has much to do with the complexity of their adoption, but also especially with their disruptive power and the tasks that are regularly performed

\footnotetext{
${ }^{9}$ See Appendix A12 for a complete list of questions used in this study.

${ }^{10}$ Switzerland shows a low amount of firm foundations and closures per year. The latest available figures show that there were 694 closures in 2014 and 845 in 2013 in total; and there were about 700 to 900 firm foundations with more than 5 employees in the same years. The annual closure rate of firms with at least 10 employees was $0.3 \%$. Given these very low numbers in the complete Swiss economy, we would expect to find 1-2 firm closures in our sample, if we could observe them. Although, we cannot rule out that these could have a significant impact on the results, the likelihood seems rather low. Since newly founded firms are not included in our sample, the results are at least not directly influenced by newly founded firms.
}

Table 1

Descriptive statistics.

\begin{tabular}{lllllll}
\hline Variable & count & mean & median & sd & min & max \\
\hline $\begin{array}{l}\text { Investment in } \\
\quad \text { digitalization }\end{array}$ & 447 & 6.20 & 0.68 & 57.82 & 0.00 & $1,204.50$ \\
$\begin{array}{l}\text { Total employees } \\
\text { High-skilled emp. }\end{array}$ & 447 & 272.80 & 98.00 & $1,057.28$ & 20.00 & $18,965.00$ \\
Mid-skilled emp. & 447 & 46.70 & 7.84 & 238.62 & 0.00 & $4,930.90$ \\
Low-skilled emp. & 447 & 175.55 & 13.30 & 130.90 & 0.00 & $1,455.52$ \\
R\&D investment & 447 & 11.38 & 0.00 & 52.08 & 0.00 & 763.02 \\
Machine-based tech. & 447 & 0.62 & na & na & 0.00 & 1.00 \\
\hline
\end{tabular}

Notes: This table provides descriptive statistics on all variables used in this study, reference year 2015. Investment in digitalization and R\&D investment are measured in CHF 100,000 (CHF $1 \cong$ USD $1.02 \cong$ EUR 0.90). Machine-based tech. indicates firms that employ at least one of the following technologies: Computerized automated control systems, programmable logical controllers, rapid prototyping, $\mathrm{CNC}$ /DNC machines, autonomous vehicles, 3D printing, radio-frequency identification (RFID), or the Internet of Things. High (mid, low)-skilled is the number of employees with a high (medium, or low) level of educational attainment, as described in detail above. Total employment is total amount of full time equivalent employment. Data source: KOF Swiss Economic Institute at ETH Zurich. The descriptive statistics for the single cross-sections are presented in the Appendix Table A2a and Table A2b. There are a few firms with less than 20 employees in 2014 (see Table A2b). If we drop these observations, the main results do not change.

by machine-based technologies in contrast to the tasks that are regularly performed by non-machine-based digital technologies. We consider the following technologies to be complex machine-based: computerized automated control systems, programmable logistic controllers, rapid prototyping, computerized numerical control (CNC) and direct numerical control (DNC) machines, robots, autonomous vehicles, 3D printing, and the Internet of Things. Technically, the crucial difference between these and non-machine-based technologies is their powerful combination of data access, computation and communication technologies with acting hardware. This often gives machinebased digital technologies their disruptive power, and it is these technologies in particular that are supposed to drive the current industrial revolution. Given the technical complexity of machine-based digitalization, their implementation is often capital intensive, requires highskilled labor, and is only profitable if it allows firms to produce at much lower cost per unit or higher quality standards than otherwise possible. Here lies another crucial difference compared to non-machine-based technologies that might sometimes be adopted with the same intentions but are in fact often 'just' used to facilitate extant single processes rather than to disrupt or significantly change the whole production process. Consider, for instance, ERP, social media or e-purchasing. For most firms, these technologies are rather easy to adopt and complement extant processes instead of substituting them. They typically do not change the core production process or set new industry standards of product production.

Finally, we argue that especially machine-based digital technologies can be seen as powerful tools that enable workers to raise their productivity as long as they are qualified and skilled enough to bring them to a fruitful usage. High skilled workers will not only more likely use these technologies as complements, but will also more likely develop new unforeseen solutions, while low-skilled workers are more likely to lack the technical know-how required to use these technologies as fruitfully. Further, the latter group of workers has a natural interest not to propose any change where machine-based technologies substitute for tasks regularly fulfilled by low skilled workers even if it would encounter it. Together with the higher complexity of machine-based as opposed to non-machine based digital technologies the relevance of advanced skills increases while medium to low skill levels face lower demand, leading in turn to heterogeneous impacts on job creation and destruction across skill levels. Although this differentiation is not 
always applicable and contradictory examples exist, we believe it is an important distinction within digital technologies and their various possible impacts on job creation and destruction.

Table A1 in the Appendix gives an overview of digital technologies used by the Swiss firms in our sample. Non-machine-based technologies like ERP, e-purchasing, and CRM are used by $79 \%, 61 \%$, and $51 \%$ of the sample firms, respectively. The diffusion rates are significantly higher in large firms than in medium-sized and small (SME) ones. A noteworthy aspect is that many firms are combining different types of digital technologies - for instance, the use of ERP to improve resource planning, and CRM to support customer relationships with specialized information. They might also allow employees to access the technological infrastructure of the firm via remote access (telework) and share information within the firm using cloud services. ${ }^{11}$ In our analyses below we separately examine firms that have adopted at least one machine-based digital technology and those that only use at least one non-machine-based technology. ${ }^{12} 62 \%$ of the firms in our sample had used at least one machine-based technology by 2016 , while $38 \%$ had only used non-machine-based technologies (Table A1 in the Appendix). High-tech manufacturing industries such as machinery, electronic and optical instruments, and vehicles show slightly higher penetration rates of machine-based technologies than low-tech manufacturing industries such as food/beverages/tobacco and basic metals (see Table A2 in the Appendix for details). There is no firm in the sample that uses no digitalization technology at all. This might be a typical outcome when firms have at least 20 employees and labor costs are high, which encourages firms across all sectors to automate their production processes. Generally, we observe a positive correlation between firm size and the rate of adoption of digital technologies.

\subsection{Methodological remarks}

The standard approach to investigate if investment in digital technologies increases or reduces the creation of jobs would be a classic ordinary least squares (OLS) regression of employment on investment in digitalization. The main issue with this approach is that we can hardly control for all kinds of firm characteristics that may simultaneously influence the creation of jobs and investment in digitalization, e.g., firms' strategy or managerial quality. A straightforward commonly used improvement over the classic OLS framework is the usage of panel estimators, where one can include firm-specific indicators that control for potential omitted variable biases from unobserved time-invariant firm characteristics. All those estimators require a strong panel component, though, i.e. information on firms observed over a long time span. In the absence of such a panel, but with information on two points in time, we can effectively control for unobserved time-invariant firm

\footnotetext{
${ }^{11}$ Technological complexity likely increases with the use of different types of technologies. Problems with interfaces, difficulties in programming/adapting standard software to the specific technological infrastructure of a firm, or training employees to efficiently use new software is likely to increase the technological complexity within a firm and might require new skills. In unreported analyses, we tried to measure technological complexity with the number of digital technologies used by a firm. We found that the average firm in our sample uses seven different digital technologies and that most firms that use machine-based technologies also use others. We do not differentiate between machine-based firms that use no non-machine-based digital technology and those firms that use only machine-based technologies, because both groups of firms do not show significant differences in terms of job creation and destruction. This is consistent with the finding that investments in digitalization by firms without machine-based digital technologies show no significant relationship with job creation and destruction. Results are available from the authors upon request.

${ }^{12}$ All results presented below are robust to excluding any single technology while keeping the others. Information on the amount of capital invested in specific digital technologies is unfortunately not available.
}

characteristics by estimating the standard model in differences. Hence, we regress the difference of the total number of employees (in a certain skill category) in the second period minus the total number of employees (in a certain skill category) in the first period on the corresponding difference in investment in digitalization. It is easy to show that this strategy is immune to any time-invariant omitted variable bias like the regular firm fixed effects estimator (Wooldridge, 2002). Formally, we estimate the following equation:

$\Delta$ Skill $_{i}=\alpha_{0}+\alpha_{1} \Delta$ diginvest_chf $_{i}+\alpha_{2} \Delta r n d_{i}+\alpha_{3} \Delta e m p_{i}+\varepsilon_{i}$

where

\section{$\Delta$ Skill $\varepsilon\{\Delta$ highskill, $\Delta$ midskill, $\Delta$ lowskill $\}$}

and $i$ is the firm index. We explicitly control for the change in R\&D expenses along the change in investment in digitalization as the former may well coincide and have similar effects on job creation and destruction. We also control for the total change in jobs to prevent our coefficient of interest $\alpha_{1}$ from capturing general firm-size changes. Owing to the estimation in differences we implicitly control for firm age and unobserved heterogeneity across industries. ${ }^{13}$ The results do not change when we control for the initial level of employment instead of the absolute change. We also find consistent results, if we use the share of workers in a given category instead of the absolute change (see Appendix, Table A5). For U.S. firms, it has been argued that imports and exports may still confound the estimation because changes in that regard might trigger investment in digitalization and employment changes alike. Fortunately, we can control for both of these factors but only for a smaller group of firms. We thus show these results as part of other sensitivity checks in the Appendix, Tables A6 and A7. Since all results presented below remained qualitatively unchanged after the inclusion of these controls, and other controls like foreign ownership and technology age (see Table A8a), we focus in our main analyses on the short model (results on all the extended models are available from the authors upon request). In alternative regressions we excluded $\Delta e m p$ from our framework, or exchanged it with firm sales as a measure of firm size, and find similar results (see Appendix, Table A10a and Table A10b).

\section{Results}

Table 2 presents the main results. We find broad support for heterogeneous effects of changes in investment in digitalization on changes in employment of workers with different skills measured by their educational attainments. Specifically, we estimate a statistically significant $(\mathrm{p}<0.01)$ increase in high-skilled employment and a statistically significant decrease in medium- to low-skilled jobs per CHF invested in digitalization. The magnitudes of the estimated effects are economically meaningful. Column 1 , Table 2, suggests that a CHF 100,000 increase in investment in digitalization is associated with about 5.8 more jobs for highly educated workers, four fewer jobs for mid-skilled workers (Column 2) and about 2.3 fewer jobs for the lowskilled (Column 3 ). In total, Column 4 suggests an increase of 1.6 jobs

\footnotetext{
${ }^{13}$ A classical labor demand function also envisages controls for labor costs and capital costs. Since we use first differences in our estimations, we can drop such controls for the following reasons. First, we look at a very short time period (2014 and 2015) with very stable economic conditions in Switzerland. There have been no changes in capital costs; the relevant interest rate (mean level of mortgages) changed by only $0.03 \%$-points (from $2.69 \%$ to $2.66 \%$ ) between January 2014 and December 2015 (see Swiss National Bank, 2017). Also, labor costs hardly changed, increasing by $0.4 \%$ between 2014 and 2015 (see FSO (Federal Statistical Office), 2017). Second, since capital costs do not vary much among industries, we address them with our first-difference approach. Wage data might cause serious endogeneity problems in single-equation settings; hence, some authors even propose omitting wage data (see e.g. Machin and Van Reenen, 1998; Arvanitis and Loukis, 2015).
} 
Table 2

Investment in digitalization and job creation and destruction.

\begin{tabular}{|c|c|c|c|c|}
\hline Variables & $\begin{array}{l}(1) \\
\Delta \text { High-skilled }\end{array}$ & $\begin{array}{l}(2) \\
\Delta \text { Mid-skilled }\end{array}$ & $\begin{array}{l}(3) \\
\Delta \text { Low-skilled }\end{array}$ & $\begin{array}{l}(4) \\
\Delta \text { Total } \\
\text { employees }\end{array}$ \\
\hline \multirow[t]{2}{*}{$\begin{array}{l}\Delta \text { Investment in } \\
\text { digitalization }\end{array}$} & $5.841 * * *$ & $-4.001 * *$ & $-2.307 * * *$ & $1.597 * * *$ \\
\hline & $(1.812)$ & $(1.902)$ & (0.399) & $(0.401)$ \\
\hline \multirow[t]{2}{*}{$\begin{array}{l}\Delta \text { Investment in R\& } \\
\quad \text { D }\end{array}$} & 0.033 & -0.033 & 0.001 & 0.003 \\
\hline & $(0.024)$ & $(0.028)$ & $(0.006)$ & $(0.032)$ \\
\hline$\Delta$ Total employees & $\begin{array}{l}0.274 * * \\
(0.129)\end{array}$ & $\begin{array}{l}0.032 \\
(0.121)\end{array}$ & $\begin{array}{l}0.660 * * * \\
(0.101)\end{array}$ & \\
\hline Observations & 447 & 447 & 447 & 447 \\
\hline Firm fixed effects & Yes & Yes & Yes & Yes \\
\hline$R^{2}$ & 0.689 & 0.348 & 0.398 & 0.117 \\
\hline
\end{tabular}

Notes: All models are estimated using OLS. All variables are measured in absolute differences between 2015 and 2014. High (mid, low)-skilled is the absolute change in employees with a high (medium, or low) level of educational attainment, as described in detail above. Investment in digitalization is the absolute change in investment in digitalization, measured in CHF 100,000. Investment in $R \& D$ is the absolute change in investment in $R \& D$, also measured in CHF 100,000. Total employment is the change in total employment. Heteroscedasticity-robust standard errors are shown in parentheses. ${ }^{* * *}, * *, *$ indicate statistical significance at the $1 \%, 5 \%$, and $10 \%$ level, respectively. Data source: ETH Zurich, KOF Swiss Economic Institute.

per CHF 100,000 invested in digitalization. The difference between this estimate and the total of the estimates from models 1 to 3 is due to the fact that we control for the total size increase in models 1 to $3 .{ }^{14}$ It suggests digitalization has a small net positive impact on employment in Switzerland at least in the short run, which is consistent with recent findings derived from a structural model based on German data (Arntz et al., 2018).

Depending on the specific situation and technology employed, the employment effects likely reflect the need for new personnel to install and implement the acquired assets, change the production process, or to bring new services and products to the market. As individuals who work on these tasks typically need to be trained in advance, the hiring of new workers may start before the actual adoption of the digital technologies, resulting in a rather quick response of employment figures to investments in digitalization. The decline in low and medium skilled employment is unlikely to reflect dismissals due to the strong employment protection in Switzerland. Negatively affected employees, however, will either learn about negative career prospects or will be informed in advance of the actual investment. Those workers may thus search for new jobs with better career prospects rather quickly, such that negative employment effects materialize within a short time frame and despite strong institutional job protection.

If we separately consider firms that employ at least one machinebased digital technology (Table 3, Columns 1-3) and the other firms (Table 3, Columns 4-6), we find that our main results are entirely driven by the group of firms that employ at least one machine-based technology. ${ }^{15}$ The impact of digital investment on high-skilled employees is not only insignificant for firms without machine-based digital technologies but also statistically significantly different from the coefficient derived for firms that adopted at least one machine-based digital technology (two-sided $t$-test, $\mathrm{p}<0.003$ ). This suggests that different types of digital technologies do indeed exert different impacts on employment. The coefficients in the mid-skilled employee regressions

\footnotetext{
${ }^{14}$ In alternative unreported regressions we used the share of skilled, medium-, and low skilled labor as alternative dependent variables. The size of the differences in shares resembles the estimated change in absolute employment for the average firm but have a weaker statistical significance, see Table A5 in the Appendix.

${ }^{15}$ The fully interacted model is presented in the Appendix, Table A9.
}

(models 2 and 5) are insignificantly different though $(\mathrm{p}=0.264)$, and the coefficients in the low-skilled employee regressions (models 3 and 6 ) only pass the one-sided test $(p=0.071) .{ }^{16}$ This result is broadly consistent with recent findings from the U.S., where the impact of the adoption of robots has been analyzed (Acemoglu and Restrepo, 2017b), but it differs in terms of the net impact our results imply. ${ }^{17}$

These results fit the view that the strongest impact of digital technologies on job creation and destruction materializes where machines are empowered by data access, computation and communication technologies. This is also the area where technological advances have been the most dynamic over the last few years, and this is supposed to be the main driver of the current industrial revolution. The fact that we do not find significant employment effects for firms that have adopted only non-machine-based technologies may not be surprising, given that previous studies have found that ICT investment does not have major impacts on either employment or productivity (e.g. Acemoglu et al., 2014; Chen and Xie, 2015). ${ }^{18}$

The change in total employment is significant positively associated with an increase in high- and low-skilled labor, suggesting that most of the general hiring of employees happens in these categories.

\subsection{IV regression}

While we effectively control for unobserved time-invariant heterogeneity plus the main suspects of time-variant covariates in our previous models, some unobserved time-varying factors might still confound the estimation. Potential candidates are unobserved changes in firm strategies, e.g. changing to a more open innovation strategy that enlarges the collaboration network. This might increase high-skilled jobs and reduce lower-skilled jobs and trigger additional investment in digital technologies to improve communication within the extended network. If such changes were common, the previously estimated positive effect of investment in digitalization on high-skilled job creation and the negative effect on low-skilled jobs would be overestimated.

To address these concerns we turn to instrumental variable regressions. In order to derive consistent estimates from an IV regression, our instrument needs to fulfill the validity requirements, i.e. it needs to explain the change in investment in digitalization while being uncorrelated with changes in the number of jobs created in different skill categories. In the present empirical setting we exploit the fact that the main ICT network provider in Switzerland was in the middle of its expansion of the high-speed broadband network right before the sample starts. We considered an internet connection to be high speed if it was based on fiber-to-the-home technology, vectoring technology, or allowed download speeds of more than $100 \mathrm{Mbit} / \mathrm{s}$. We obtained data on the regional expansion of the Swisscom ${ }^{19}$ fiber and vector network for 2014 , which by then covered about $60 \%$ of the firms in our sample. Since it is the predominant - but not the only - way to get a fast internet connection in Switzerland, we supplemented it with survey data on whether firms would actually have access to high-speed internet even

\footnotetext{
${ }^{16}$ The two-sided test reveals a p-value of 0.1423 .

${ }^{17}$ Since we take into account not only robots but also other applications like the Internet of Things, it may not be surprising that the results differ somewhat. All results presented in Table 3 are even more pronounced in terms of statistical significance if we only consider firms that use robots among those that have adopted a machine-based digital technology. We also note differences in the institutional environments of both settings, which might play an important role too (see also the discussion below).

${ }^{18}$ Arvanitis and Loukis (2009) found small positive effects of ICT investment on the productivity of Swiss firms in 2004 but did not consider employment effects. They did not control for unobserved time-invariant heterogeneity either, which might have revealed different findings.

${ }^{19}$ Swisscom is the incumbent in the Swiss telecommunications market and the dominant provider of fixed-line telecommunications infrastructure. Sunrise and Cablecom are the main, albeit significantly smaller, competitors.
} 
Table 3

Investment in digitalization - machine-based versus non-machine-based.

\begin{tabular}{|c|c|c|c|c|c|c|}
\hline \multirow[b]{2}{*}{ Variables } & \multicolumn{3}{|l|}{ Machine-based } & \multicolumn{3}{|c|}{ Non-machine-based } \\
\hline & $\Delta$ High-skilled & $\Delta$ Mid-skilled & $\Delta$ Low-skilled & $\Delta$ High-skilled & $\Delta$ Mid-skilled & $\Delta$ Low-skilled \\
\hline$\Delta$ Investment in digitalization & $\begin{array}{l}6.247 * * * \\
(1.581)\end{array}$ & $\begin{array}{l}-4.046^{* *} \\
(1.840)\end{array}$ & $\begin{array}{l}-2.728^{* * *} \\
(0.377)\end{array}$ & $\begin{array}{l}0.147 \\
(0.174)\end{array}$ & $\begin{array}{l}-1.178 \\
(1.307)\end{array}$ & $\begin{array}{l}1.048 \\
(1.327)\end{array}$ \\
\hline$\Delta$ Investment in $\mathrm{R} \& \mathrm{D}$ & $\begin{array}{l}0.032 \\
(0.022)\end{array}$ & $\begin{array}{l}-0.034 \\
(0.024)\end{array}$ & $\begin{array}{l}0.002 \\
(0.005)\end{array}$ & $\begin{array}{l}0.226 \\
(0.299)\end{array}$ & $\begin{array}{l}0.238 \\
(1.077)\end{array}$ & $\begin{array}{l}-0.530 \\
(1.235)\end{array}$ \\
\hline$\Delta$ Total employees & $\begin{array}{l}0.368^{* *} \\
(0.167)\end{array}$ & $\begin{array}{l}-0.124 \\
(0.149)\end{array}$ & $\begin{array}{l}0.734 * * * \\
(0.111)\end{array}$ & $\begin{array}{l}-0.102 \\
(0.093)\end{array}$ & $\begin{array}{l}0.585^{* * * *} \\
(0.063)\end{array}$ & $\begin{array}{l}0.458^{* * *} \\
(0.133)\end{array}$ \\
\hline Observations & 277 & 277 & 277 & 170 & 170 & 170 \\
\hline Firm fixed effects & Yes & Yes & Yes & Yes & Yes & Yes \\
\hline$R^{2}$ & 0.762 & 0.458 & 0.601 & 0.165 & 0.189 & 0.136 \\
\hline
\end{tabular}

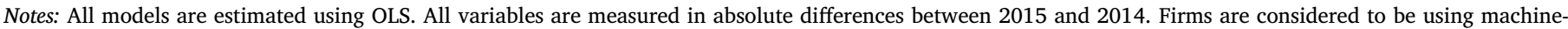

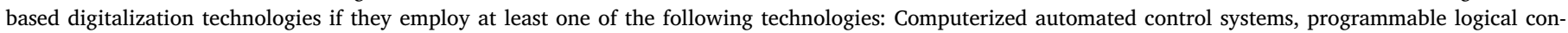

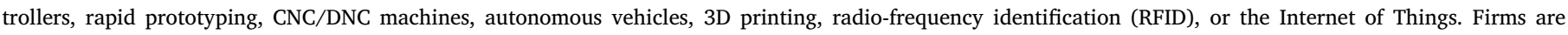

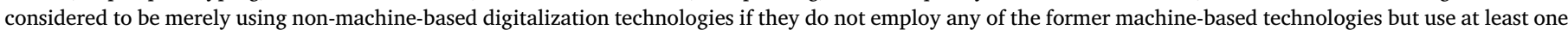

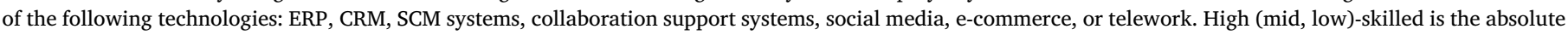

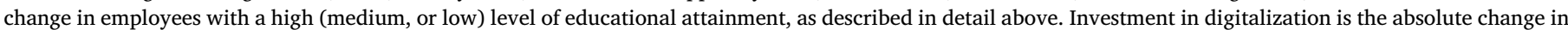

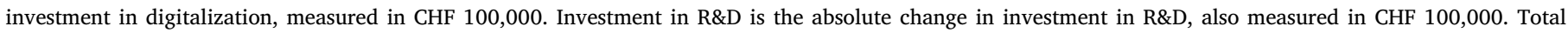

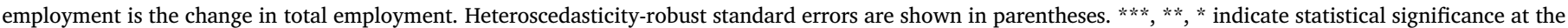
1\%, 5\%, and 10\% level, respectively. Data source: ETH Zurich, KOF Swiss Economic Institute.

without Swisscom network coverage. Based on this information, we defined our instrument as being a dummy that has a value of one if a firm is covered by the Swisscom network or has another type of highspeed internet access, and is zero otherwise.

We would argue that a fast internet connection should have triggered investment in digitalization because most digital technologies require such infrastructure in order to be implemented and used effectively. Indeed, we find this view supported by the first stage of our IV regression (see Table A11 in the Appendix). The instrument is individually significant, but the strength is lower than expected. The Ftest on individual instrument strength reveals a value of 3.02 (3.83 in the sub-sample of machine-based digital technology adopters), while it is generally recommended to have a strength of ten or more to be on the safe side (Stock and Yogo, 2005). The rather weak instrument calls for a very cautious interpretation because IV regressions can be even more biased than OLS regressions in such cases (see Young, 2018, for an extend discussion of weak instrument biases and violation of the exclusion restriction). Since we also have only one instrument, we cannot formally test the exclusion restriction, i.e. whether the instrument is indeed uncorrelated with the error term of the second stage. The fact that it is not directly related to our depended variable, or other firm characteristics, suggests that it may still work. We acknowledge that it is not perfect, and it could be correlated with some unobserved regional characteristics that are in turn correlated with firms' investment in digitalization and/or job creation. One noteworthy aspect is that such correlations may formally violate the exclusion restriction but do not necessarily cause huge biases (Conley et al., 2012). Overall, a very careful assessment of the IV results is warranted although our results based on the previously estimated models generally hold up in this setup, as Table 4 shows. The coefficients are in all models of high- to low-skilled jobs similar to those estimated previously. The statistical significance drops quite a bit in the full sample (models 1 to 3), where only the positive impact of investment in digitalization on high-skilled jobs remains significant at conventional levels. In the sub-sample of firms that have adopted machine-based digital technologies we still find the impact to be statistically significant $(\mathrm{p}<0.05)$ on high- as well as low-skilled employment. ${ }^{20}$ That the statistical significance drops quite a

\footnotetext{
${ }^{20}$ Similar to the standard OLS results presented above we do not find any significant effects in the sub-sample of firms that do not use any machine-based digital technology. Results are available from the authors upon request.
}

bit compared to the OLS results is not surprising because of the two step procedure, which makes estimates less precise compared to OLS, all else equal. The magnitudes of the coefficients estimated with OLS and IV are statistical insignificant, although the sizes of the coefficients nominally differ quite a bit with respect to medium and low-skilled labor. Under the assumption that our IV estimates are not biased, the nominally lower effect of investment in digitalization on medium skilled labor might be the result of unobserved training programs that are offered to medium skilled employees at the same time when changes caused by the adoption of digital technologies apply. The seemingly underestimated effect of changes in low-skilled labor in the OLS case might stem from unobserved severance payment offers to this group of workers, potentially because it is harder to retrain low-skilled workers than medium skilled works to fulfill new tasks created in the wake of the digital transformation.

Overall, our results suggest that investment in digitalization does indeed have a significant impact on job creation and destruction. The impact is, however, heterogeneous across skill levels and technologies something that has received little attention in the literature so far.

\subsection{Limitations and discussion}

Although we carried out an extensive set of robustness and sensitivity checks, some limitations that warrant attention remain, partly because they give rise to fruitful future research venues. First of all, while we link investment in digitalization to employment across different skill levels within firms, unfortunately we cannot observe how much has been invested in specific digital technologies and when those technologies were actually adopted. Appendix Tables A8b to A8d actually show that our findings are more pronounced the more technologies are used for more than two years, indicating that the long termeffects might be stronger than the short-term effects and that technology age might be a crucial factor driving our results. Further, as our results suggest that differentiation among digital technologies is crucial, we would not be surprised to see heterogeneous effects even within the machine-based technologies and different kinds of non-machine-based technologies. Heterogeneity in employment effects may also result from the fact that technologies are applied for different purposes, at different stages of the production process, and at different stages of their maturity. For a deeper understanding it would thus be invaluable to examine where and how exactly each digitalization technology is applied. We conjecture that the mechanisms through which each technology 
Table 4

IV regressions - full sample and machine-based digital technology adopters only.

\begin{tabular}{|c|c|c|c|c|c|c|}
\hline \multirow[b]{2}{*}{ Variables } & \multicolumn{3}{|l|}{ Full sample } & \multicolumn{2}{|l|}{ Machine-based } & (6) \\
\hline & $\Delta$ High-skilled & $\Delta$ Mid-skilled & $\Delta$ Low-skilled & $\Delta$ High-skilled & $\Delta$ Mid-skilled & $\Delta$ Low-skilled \\
\hline$\Delta$ Investment in digitalization (est.) & $\begin{array}{l}6.539^{* *} \\
(2.550)\end{array}$ & $\begin{array}{l}-4.184 \\
(3.406)\end{array}$ & $\begin{array}{c}-2.587 \\
(2.628)\end{array}$ & $\begin{array}{l}6.449 * * * \\
(2.398)\end{array}$ & $\begin{array}{l}-2.525 \\
(3.119)\end{array}$ & $\begin{array}{l}-4.269^{* *} \\
(1.987)\end{array}$ \\
\hline$\Delta$ Investment in $R \& D$ & $\begin{array}{l}0.032 \\
(0.027)\end{array}$ & $\begin{array}{l}-0.033 \\
(0.028)\end{array}$ & $\begin{array}{l}0.001 \\
(0.006)\end{array}$ & $\begin{array}{l}0.032 \\
(0.023)\end{array}$ & $\begin{array}{l}-0.035^{* *} \\
(0.018)\end{array}$ & $\begin{array}{l}0.003 \\
(0.008)\end{array}$ \\
\hline$\Delta$ Total employees & $\begin{array}{l}0.224 \\
(0.168)\end{array}$ & $\begin{array}{l}0.046 \\
(0.240)\end{array}$ & $\begin{array}{l}0.681^{* * *} \\
(0.199)\end{array}$ & $\begin{array}{l}0.350 \\
(0.214)\end{array}$ & $\begin{array}{l}-0.257 \\
(0.272)\end{array}$ & $\begin{array}{l}0.868^{* * *} \\
(0.150)\end{array}$ \\
\hline Observations & 447 & 447 & 447 & 277 & 277 & 277 \\
\hline Firm fixed effects & Yes & Yes & Yes & Yes & Yes & Yes \\
\hline$R^{2}$ & 0.682 & 0.347 & 0.395 & 0.762 & 0.409 & 0.490 \\
\hline
\end{tabular}

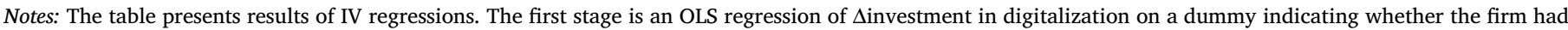

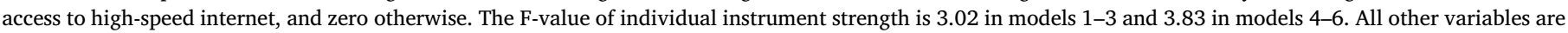

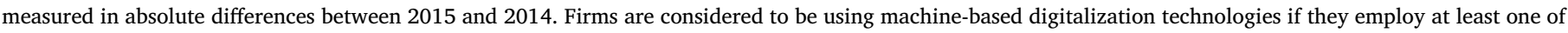

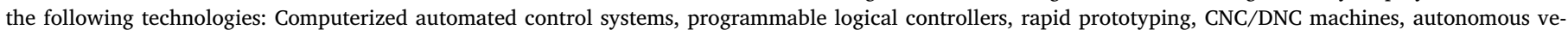

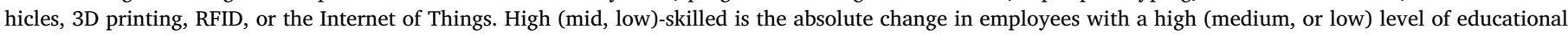

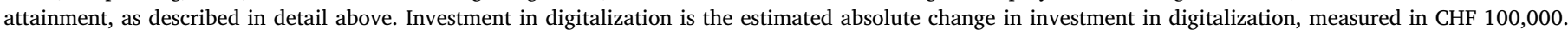

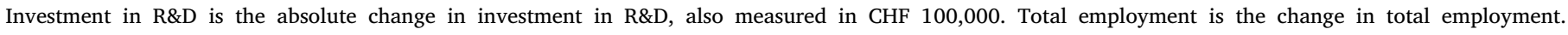

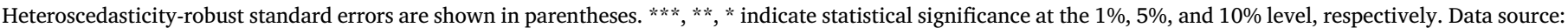
ETH Zurich, KOF Swiss Economic Institute.

contributes to job creation and destruction will be quite heterogeneous. As such, industry-, technology- or even firm-specific analyses that focus on one specific technology such as robots or autonomous cars would appear to be fruitful avenues for future research. When such research is carried out, attention should also be given to measuring the market impact of digital technologies.

Second, we need to keep in mind that our sample covers a specific time period when the business cycle was in an upswing and digital technologies were considered to be much more disruptive than during previous years. Recent advances in economic theory suggest that the observed spread in demand for high-skilled and low-skilled employees is part of the digitalization process and is expected to be most pronounced in the middle of the transition phase from a non-digitalized economy to a fully digitalized one (Acemoglu and Restrepo, 2017a). This means that our estimates may change over the course of the next few years towards a more mature technological environment. The sample is further limited by its restriction to firms with at least 20 employees. The relationship between investment in digitalization and job creation might thus look different for very small firms in general and the increasingly popular entrepreneurial firms in specific. It should also be mentioned again that our IV regression is far from perfect, such that a very careful interpretation is warranted. There might still be unobserved time-varying factors that are correlated with investment in digitalization and employment in different skill groups, which might cause our estimates to be biased up- or downwards, respectively. Potential candidates are changes to a more open innovation strategy that enlarges the collaboration network. This might increase high-skilled jobs and reduce lower-skilled jobs and trigger additional investment in digital technologies to improve communication within the extended network. If such changes were common, the previously estimated positive effect of investment in digitalization on high-skilled job creation and the negative effect on low-skilled jobs would be overestimated.

Third, vocational (dual) education is an important part of the Swiss education system, and officials quite frequently assume that it accounts for the country's low unemployment rates. The presented results and other empirical evidence suggest that the digitalization process reduces employment not only for low-skilled workers but also, at least to a lesser extent, for mid-skilled employees as well (Siegenthaler and Stucki, 2015). Given that the private sector is strongly involved in the design of courses, ensuring great flexibility and practical relevance for training, the digital challenges might be beyond the system's capacity to adapt (Renold et al., 2016). It may require a redesign of the vocational education system to prevent further employment losses, especially if it turns out that the observed reduction is not temporary.

Fourth, it should be emphasized that our empirical setting refers to a highly developed country that is often considered to be among the technological leaders in the world, while also having one of the besteducated workforces with quite a unique educational system. The latter in particular should give us pause for thought when extrapolating the presented results to other countries of the world. Because of the high wages and liberal migration policy it should be easier for Swiss firms to hire highly educated workers than for many firms situated outside Switzerland. The expected returns to firms' investment in digitalization may thus be much higher than at other places in the world. Furthermore, the specific institutional background may cause Swiss firms to invest in different kinds of digital technologies and with different aims than firms in other countries. Given the high salaries in the low-skilled sector, for instance, investment in automation may generate larger pay-offs than in countries with relatively cheap labor.

Although we have no systemic evidence, it appears that the current rise of digital technologies may exert similar effects on job creation and destruction as previous technological disruptions. It is striking that, consistent with our results, most modern jobs require a higher skill level than many jobs of the past, especially those commonly found before the second industrial revolution. One of the reasons why the second industrial revolution did not cause mass unemployment in the long run (contrary to prominent assessments of the time) may be that the capacities of the educational sector increased accordingly, ensuring that the new demand for high-skilled labor is met. There might be reasons to believe this time could be dramatically different ${ }^{21}$, but the slightly positive net effect that we have identified in the present paper might well be taken as a reason to feel less pessimistic about the changes to come. We acknowledge, though, that it is in fact not possible to empirically identify the true net effect without a structural model.

\section{Conclusions and policy implications}

The emerging digitalization of the economy is expected to have a tremendous impact on several economic parameters, particularly on the

\footnotetext{
${ }^{21}$ One could argue that this time is dramatically different because machines pose a challenge for intelligent work rather than mainly manual labor as in the past.
} 
number of jobs and the skills required to perform those jobs. The present paper has addressed this topic with econometric analyses based on unique firm-level microdata from Switzerland, one of the technological leaders of the world. We found robust evidence on the relationship between changes in investment in digital technologies within the firm and employment changes within the firm, explicitly considering heterogeneity in terms of different skill levels and different types of digital technologies.

Specifically, we found that investment in digital technologies is positively associated with employment of high-skilled workers and negatively associated with employment of low-skilled workers, with an overall positive net effect on employment. These effects are entirely driven by machine-based digital technologies (robots, 3D printing, the Internet of Things) that are supposed to fuel the current industrial revolution. We find no significant impact of investment in digitalization when only firms that adopt non-machine-based digital technologies, such as ERP, e-commerce or cooperation support systems, are considered.

This evidence improves our understanding of the potential economic implications of the digitalization process, where digital technologies are constantly changing methods of production and constantly generating new products and services. The breakthrough of machinebased digital technologies required better technological infrastructure (faster internet connections, ubiquity of internet access, cloud technologies, etc.), the skills to develop such technologies, and sufficiently skilled workers to use them effectively. Meeting these requirements over recent years has accelerated the transformation of the economy into the digital age. This transformation process does not come without frictions, though. While our estimations imply that total employment will slightly grow in the current transition period, the average masks an increase in employment of skilled labor and a decrease in employment of unskilled labor. The result runs counter to the unconditional statement that workers are in a race against machines - at least in the short run and for technologically advanced, open economies with a large share of high-skilled labor, like Switzerland. This has implications for corporate as well as political leaders.

The global war for talent is likely to intensify further. Companies should therefore prepare to spend more time and resources on recruiting and retaining skilled employees. In times of high demand and an increasingly mobile workforce, even well-situated companies might face strong competition for their most talented employees in the future. Many firms in Switzerland, a country with one of the highest proportions of well-educated people, argue already that a shortage of highly qualified workers would limit their growth.

In combination with a decrease of jobs for low-skilled workers, inequality within the population is likely to increase. From an economic perspective, it is thus crucial to develop and apply instruments that minimize potential negative impacts while nurturing positive effects. As long as medium- and low-skilled workers can be trained to learn new skills that enable them to take over new tasks created in the wake of the digitalization process, the promotion of such professional training programs could be very helpful for the affected individuals and the economy alike. Professional training and educational attainment programs should not be seen as an all-purpose medicine, however, since physical or mental limitations may constrain their effective usage. In such cases different instruments need to be provided, and digital technologies themselves might actually offer a solution. Collaborative artificial intelligences, for instance, might enable medium and lowskilled workers to focus on tasks where they have a comparative advantage over machines, e.g. any work that requires personal emotional interaction, while machines substitute for personal weakness, e.g. in predicting prices and recognizing patterns. This would increase the individual productivity of medium and low-skilled workers, which should in turn create new job opportunities. If such efforts fail, inequality among workers is likely to rise, which poses a great challenge for public institutions and policymakers.
There are three main objectives that policymakers could pursue to address these challenges. First, it is of utmost importance for the competitiveness of a technologically advanced country to ensure that skilled labor is efficiently allocated to growing, productive sectors. This implies flexible labor markets and workable product market competition to provide incentives to invest in innovation and the adoption of new technologies. For small countries in particular it is important that the worldwide free movement of talent is guaranteed and the hiring process is accompanied by low administrative costs. Second, training and continuing professional development is necessary to improve the match between skills and job requirements. This includes training not only in technical skills but also soft skills and emotional skills to manage the digital transition of labor markets. Since the ability to learn and retrain skills is positively correlated with educational attainment, governments should increase the attractiveness of tertiary education. Third, some parts of society might not be able (or willing) to successfully manage the transition to a digital age. This could be addressed by the development of collaborative artificial intelligences as mentioned above or innovative social measures such as an unconditional basic income.

\section{Appendix A. Supplementary data}

Supplementary material related to this article can be found, in the online version, at doi:https://doi.org/10.1016/j.respol.2019.03.010.

\section{References}

Acemoglu, D., Restrepo, P., 2017a. The Race Between Man and Machine: Implications of Technology for Growth, Factor Shares and Employment. Working Paper.

Acemoglu, D., Restrepo, P., 2017b. ). Robots and Jobs: Evidence From US Labor Markets. Working Paper.

Acemoglu, D., Dorn, D., Hanson, G.H., Price, B., 2014. Return of the Solow paradox? IT, productivity, and employment in US manufacturing. Am. Econ. Rev.: Papers Proc. 104, 394-399.

Arntz, M., Gregory, T., Lehmer, F., Matthes, B., Zierahn, U., 2016. Arbeitswelt 4.0 - Stand der Digitalisierung in Deutschland: Dienstleister haben die Nase vorn. IABKurzbericht Nr. 2.

Arntz, M., Gregory, T., Zierahn, U., 2017. Revisiting the risk of automation. Econ. Lett. $159,157-160$.

Arntz, M., Gregory, T., Zierahn, U., 2018. Digitalisierung und die Zukunft der Arbeit: Makroökonomische Auswirkungen auf Beschäftigung, Arbeitslosigkeit und Löhne von morgen. Bundesministerium für Forschung und Entwicklung (BMBF), Mannheim.

Arvanitis, S., Loukis, E.N., 2009. Information and communication technologies, human capital, workplace organization and labour productivity: a comparative study based on firm-level data for Greece and Switzerland. Inf. Econ. Policy 21, 43-61.

Arvanitis, S., Loukis, E., 2015. Employee education, information and communication technologies, workplace organization, and trade: a comparative analysis of Greek and Swiss firms. Ind. Corp. Chang. 24 (6), 1417-1442.

Arvanitis, S., Veseli, K., Woerter, M., 2014. Die Tertiärisierung der Volkswirtschaft setzt sich fort. Die Volkswirtschaft Nr.3/2014.

Arvanitis, S., Grote, G., Spescha, A., Wäfler, T., Woerter, M., 2017. Digitalisierung in der Schweizer Wirtschaft: Ergebnisse der Umfrage 2016. KOF Studie Nr. 93, Juni. ETH Zürich, KOF Konjunkturforschungsstelle, Zürich.

Aubert-Tarby, C., Escobar, O.R., Rayna, T., 2018. The impact of technological change on employment: the case of press digitisation. Technol. Forecast. Soc. Change 128, 36-45.

Autor, D., 2015. Why are there still so many jobs? The history and future of workplace automation. J. Econ. Perspect. 29 (3), 3-30.

Autor, D., Levy, F., Murnane, R.J., 2003. The skill content of recent technological change: an empirical exploration. Q. J. Econ. 118, 1279-1333.

Balsmeier, B., Delanote, J., 2015. Employment growth heterogeneity under varying intellectual property rights regimes in european transition economies: young vs. mature innovators. J. Comp. Econ. 43, 1069-1084.

Blanchflower, D., Burgess, S., 1999. New technology and jobs: comparative evidence from a two country study. Econ. Innov. New Technol. 5, 109-138.

Bolli, T., Renold, U., Woerter, M., 2017. Vertical educational diversity and innovation performance. Econ. Innov. New Technol (in print).

Bris, A., Cabolis, C., IMD World Digital Competitiveness Ranking 2018, 2017.

Brynjolfsson, E., McAfee, A., 2016. The Second Machine Age. W. W. Northon Company Inc.

Chandler, A.D., 1977. The Visible Hand: The Managerial Revolution in American Business. Harvard University Press, Cambridge, MA.

Chen, S., Xie, Z., 2015. Is China's e-governance sustainable? Testing Solow IT productivity paradox in China's context. Technol. Forecast. Soc. Change 96, 51-61.

Conley, T.G., Hansen, C.B., Rossi, P.E., 2012. Plausibly exogenous. Rev. Econ. Stat. 94 (1), 260-272. 
Dengler, K., Matthes, B., 2015. Folgen der Digitalisierung für die Arbeitswelt. Substituierbarkeitspotenziale von Berufen in Deutschland. IAB - Forschungsbericht, 11-2015. Nürnberg, Germany. .

Entorf, H., Pohlmeir, W., 1990. Employment, innovation and export activity. In: Florens, J., Ivaldi, M., Laffont, J.J., Laisney, F. (Eds.), Microeconometrics: Surveys and Applications. Oxford Blackwell, pp. 394-415.

Eurostat, 2016. Employment and Activity, Total Employment Resident Population Concept. Labour Force Survey, Last Update 11.10.2017. Luxembourg. .

Ford, M., 2015. The Rise of the Robots. Basic Books, New York.

Frey, C.B., Osborne, M.A., 2017. The future of employment: how susceptible are jobs to computerization? Technol. Forecast. Soc. Change 114, 254-280.

FSO (Federal Statistical Office), 2016. Arbeitskosten je geleistete Stunde im Produktionsund Dienstleistungssektor - Vergleich Schweiz - Europäische Union (EU) - EFTAStaaten; in Euro und KKS. Schweizer Lohnstrukturerhebung, Neuchâtel, Schweiz.

FSO (Federal Statistical Office), 2017. Schweizerischer Lohnindex: Index und Veränderungen auf der Basis 2010 $(=100)$ (NOGA 2008). Neuchâtel, Schweiz. .

FSO (Federal Statistical Office), 2018a. Educational Attainment of the Population by Occupation Pursued (ISCO Main Occupational Group) and Highest Level of Education Completed, 2017. Swiss Labour Force Survey (SAKE).

FSO (Federal Statistical Office), 2018b. STATENT Ergebnisse 2005 - 2016, Beschäftigte und Vollzeitäquivalente nach Wirtschaftszweigen auf Ebene Arbeitsstätten und nach Kantonen. Federal Statistical Office, Neuchâtel 2018.

FSO (Federal Statistical Office), 2018c. Struktur der Schweizer KMU 2016. Neuchâtel, 2018. .

Goos, M., Manning, A., 2007. Lousy and lovely jobs: the rising polarization of work in Britain. Rev. Econ. Stat. 89 (1), 118-133.

Goos, M., Manning, A., Salomons, A., 2009. Job polarization in Europe. Am. Econ. Rev.: Pap. Proc. 99 (2), 58-63 2009.

Keupp, M.M., Gassmann, O., 2013. Resource constraints as triggers of radical innovation: longitudinal evidence from the manufacturing sector. Res. Policy 42 (8), 1457-1468.

Kogan, L., Papanikolaou, A., Seru, A., Stoffman, N., 2017. Technological innovation, resource allocation and growth. Forthcoming: Q. J. Econ. 132 (2), 665-712.

Landes, D., 1969. The Unbound Prometheus. Cambridge University Press, New York.

Lehmer, F., Matthes, B., 2017. Auswirkungen der Digitalisierung auf die Beschäftigungsentwicklung in Deutschland. Institut für Arbeitsmarkt- und Berufsforschung, Aktuelle Berichte 05/2017.

Leontief, W., 1952. Machines and Man. Scientific American.

Machin, S., Van Reenen, J., 1998. Technology and changes in skill structure: evidence from seven OECD countries. Q. J. Econ. 18, 1215-1243.

Mastrostefano, V., Pianta, M., 2009. Technology and jobs. Econ. Innov. New Technol. 18
(8), 729-741.

Michaels, G., Natraj, A., Van Reenen, J., 2014. Has ICT polarized skill demand? Evidence from eleven countries over twenty-five years. Rev. Econ. Stat. 96 (1), 60-77.

Mokyr, J., 1990. The Lever of Riches: Technological Creativity and Economic Progress. Oxford University Press, New York.

Oesch, D., Rodriguez Menes, J., 2011. Upgrading or polarization? Occupational change in Britain, Germany, Spain and Switzerland, 1990-2008. Socioecon. Rev. 9 (3), $503-531$.

Pianta, M., 2006. Innovation and employment. In: Fagerberg, J., Mowery, D.C. (Eds.), The Oxford Handbook of Innovation. Oxford University Press, Oxford, United Kingdom, pp. 568-598 chapter 21.

Podsakoff, P., MacKenzie, S., Lee, J., Podsakoff, N., 2003. Common method biases in behavioral research: a critical review of the literature and recommended remedies. J. Appl. Psychol. 88 (5), 879-903.

Rayna, T., Striukova, L., Darlington, J., 2015. Co-creation and user innovation: the role of online 3D printing platforms. J. Eng. Technol. Manag. 37, 90-102.

Renold, U., Bolli, T., Caves, K., Buergi, J., Egg, M.E., Kemper, J., Rageth, L., 2016. Feasibility Study for a Curriculum Comparison in Vocational Education and Training Intermediary Report II: Education-employment Linkage Index. KOF Studies No. 80. ETH Zurich, Zurich.

Rifkin, J., 2013. The Third Industrial Revolution: How Lateral Power Is Transforming Energy, the Economy, and the World. Macmillan, USA.

Schwab, K., 2016. The Global Competitiveness Report 2016-2017. World Economic Forum.

Siegenthaler, M., Stucki, T., 2015. Dividing the pie: firm-level determinants of the labor share. Ind. Labor Relat. Rev. 68 (5), 1157-1194.

Smolny, W., 1998. Innovation, prices and employment: a theoretical model and an application for West German manufacturing firms. J. Ind. Econ. 46, 359-381.

Stock, J., Yogo, M., 2005. Testing for weak instruments in linear IV regression. Andrews DWK Identification and Inference for Econometric Models. Cambridge University Press, New York.

Swiss National Bank, 2017. Published Interest Rates for Variable Mortgages 2014/ 1-2015/12. Zurich. Switzerland. .

Van Reenen, J., 1997. Employment and technological innovation: evidence from U.K. Manufacturing firms. J. Labor Econ. 15, 255-284.

Wooldridge, J.M., 2002. Econometric Analysis of Cross Section and Panel Data. The MIT Press, Cambridge, MA.

Young, A., 2018. Consistency Without Inference: Instrumental Variables in Practical Application. Unpublished manuscript. London School of Economics and Political Science, London. 